\title{
The Market Expansion of E-Commerce to the Countryside-Taken Cloud Farm Model as an Example
}

\author{
Zhenghe Hao, a , Qianyi Song, b, Haiyun Yang ${ }^{1, c}$ \\ ${ }^{1}$ School of management, Minzu University of China, BeiJing 100000, China; \\ ahaozhenghe@126.com, b251318954@qq.com, cyhy08sea@163.com
}

Keywords: E-commerce; agricultural enterprise; business model

\begin{abstract}
In China, E-commerce, which has extended from cities to the countryside, is an effective and efficient way to transform and upgrade the traditional agricultural production mode by the integration of agriculture and e-commerce, which stimulates the internal vitality of the agricultural industry. Based on the experiences of the "Cloud Farm" model, this paper discusses and summarizes the procedures and advantages of the existing "agriculture + Internet" model, and provides suggestions for future practice, including "down to earth" which means keeping close connection with farmers and front-line staffs and "access to the cloud" which aims by making full use of the internet to integrate relatively independent part of business.
\end{abstract}

\section{Introduction}

Domestic agricultural material enterprises in China began to have a shot at electronic commerce of agricultural material in 2008, however, the results of their efforts were not plenteous. Not until 2014, with the introduction and implement of the "internet plus" policy and other governmental support policies, did the E-commerce of agricultural material start to enter into a relatively rapid development stage.

In 2014, Alibaba launched the plan called Thousand County village plan, in which 10 billion Yuan were invested, and 1000 county-level operation centers and 100,000 village service stations were built within following three to five years, in order to make their E-commerce business covering one third of the counties and one in six rural areas available by encouraging the formation of offline service entities. In August 2015, JDcom launched its online agricultural material channel, with which, JDcom built 600 county-level service centers and recruited 100,000 rural extension agents only in half a year. Besides, along with its existing base of 2000 regional distribution sites which had already been established and nearly 30 thousand self-employed distribution team, JDcom gradually opened the market about the E-commerce of agricultural material. At the same time, lots of traditional agricultural material enterprises, such as Sino-Agri, Zhejiang AMP incorporation, Sierte, and Xinjiang-Agri, speeded up their pace of the E-commerce progress. And, the third-party platforms which were unwilling to fall behind, including Kingenta commercial No1, RGRICOM, Agricultural doctor, N1.com, took various measures to catch up, and finally, put the concept of agricultural material online into the practice.

\section{The emergence of the Cloud Farm}

Founded in February 2014, the Cloud Farm is a joint venture of China Modern Agricultural Farm Alliance and Beijing Tianchen Cloud Farm. The Cloud Farm provides a platform of national online agricultural trade and high-tech service, which integrates various value-added services mainly including trade service of fertilizer, seeds, pesticides, and farm machinery, agricultural technology services, farm finance, rural logistics, and customized agricultural products. As of June 2015, there have been over 400 kinds of agricultural products from more than 400 enterprises sold online. The number of platform registered users has reached more than one million. More than 300 county-level service centers and more than 25,000 village-level service stations have been established in this 
project, covering over 10 provinces and autonomous regions including Shandong, Henan, Jiangsu, Hebei, Liaoning, and Inner Mongolia. The service covers an area of nearly 3 Million mus. Because of their outstanding performance in the innovation of business model and sales performance, which promptly attracted the appreciation of the capital market, in March and July 2015, Lenovo Holdings Limited and Chunxiao Capital respectively signed strategic investment protocols with Cloud Farm to jointly deploy a new agro-industry ecosystem.

Based on the village station and the soil testing \& fertilizer station, the Cloud Farm has deeply explored the rural market to serve the peasants and develop agriculture. In the process, a standardized e-commerce service system based on the village station model was established. The soil testing and fertilizer service not only meets the needs of farmers but also further reduces the purchase cost of peasants' agricultural materials and improves soils in rural areas. Centered with the development of agricultural modernization, the Cloud Farm has set up a variety of value-added services such as Taxi for Rural Goods, 5fengshou.com, nongjibao.189.cn, Farming Treasures, and Technology Treasures. Thus, all-round modern agriculture Service ecosystem agriculture, including pre-natal, mid-production, and the post-natal, has been finally formed.

\section{The business model of Cloud Farm}

\section{1 "Two concentrations" in the business model}

The first concern is upstream concentration (concentration on suppliers, products, and brands). The Cloud Farm integrates a large number of agribusiness suppliers, such as $\mathrm{Cp}$ Group, SKF, and SHIBEIMEI who have good product quality, high credit standing, and wide brand reputation, with the help of online e-commerce platform. By skipping the traditional part of dealers, farmers can buy high-quality agricultural materials below the market price at $20 \%$ to $40 \%$. With "cheap" and "high-fidelity", upstream concentration has solved peasant's pain points about agricultural materials purchase. Further, this achieves that agricultural products and services from circulation begin to benefit farmers, and makes it available to control the price of upstream suppliers and effectively reduce the market price and relevant risk.

Secondly, there is the downstream concentration (land and producer concentration). This is due to the quickening transfer of rural land. Circulation of rural land refers to that, under the premise of the rural collective ownership of land, farmers who own the land management right transfer the possession of the contractual operation right of land to other farmers or economic organizations. As of 2014, the transfer area of rural land in the country has reached 380 million mus, accounting for $28.8 \%$ of the total arable land in the country. At the same time, there were 3.67 million major specialized investors of all kinds and 980,000 cooperatives. Due to the explosive growth of land transfer rates, the traditional production model of "small-scale farmers" has been replaced by the new intensive model of production and plantation. Under such new modes of production, the large grower is going to pay more attention to the credibility and brand of agricultural material enterprises and integrate services including technical guidance, soil testing formula, training, two-way circulation.

\section{2 "Internet + high-tech" solution to the problems in China's traditional agriculture}

Based on the village station and farmer service center, the agricultural ecosystem has been formed through the implementation of various value-added services such as Agricultural Resources Exchange, 5fengshou.com, Soil Testing and Fertilizer, Taxi for Rural Goods, Agricultural Technology and Cloud Agriculture, etc. In this process, the "Internet + agriculture + high-tech" business model has also been established. These together solved the inevitable problems and obstacles in the development of the E-commerce of agricultural material.

Firstly, the Cloud Farm banded with several banks to develop secured transaction systems that are intended to ensure the environmental security of e-commerce prepayment and solve the severe and conventional issue of the credit transaction.

Secondly, based on the network of the village service station, the Cloud Farm makes the farmers' 
contact with E-commerce business available and easy. The nature of agriculture and the industry of agricultural materials determine that the E-commercialization of agricultural materials not only connect agricultural materials of production with the Internet of Things. The more essential consideration is how to use the Internet to attract and motivate farmers and activate the overall situation. In China, there has always been the statement that "People who farm cannot be able to make use of the Internet, and vice versa". Although, with the deepening development and popularization of Internet technology, the speed of rural e-commerce development and the number of shopping have been rapidly rising year by year. Moreover, it is not difficult to find that young people are the main force of rural e-commerce online shopping through analyzing the age level of users. Correspondingly, the main force of planting is mostly middle-aged and elderly people who do not have access to the Internet and are not good at using mobile phones. In response to this challenge, Cloud Farm first established a national standardized service network, using county-level service centers, village-level service stations, and farmer service centers (soil testing and fertilizer stations) model to keep close contact with farmers and provide lean services to users.

Thirdly, the Cloud Farm's thorough system of offline and after-sale services provides a guarantee for agricultural products and after-sale technical service issues, as well as laid the foundation for the subsequent precision and standardization of agricultural products sales.

Fourthly, with two-track, "Taxi for Rural Goods" and "Cloud Knight", the Cloud Farm commits to pave the "last-mile" road for the smooth operation of the E-commerce of agricultural material.

Fifth, Cloud farm is not just an online agricultural mall, but also a high-tech Internet platform offering agricultural integrated service. Cloud Farm's online platforms, such as "Cloud Agriculture", "Agricultural Technology" and "5fengshou.com ", provide various value-added services for peasants free of charge and build a high-tech ecosystem for the agricultural Internet with information, science and, technology, logistics and finance as the core.

\section{Summary}

As the first pathfinder and practitioner in the field of the E-commerce of agricultural material, the fundamental reason why the Cloud Farm has become a leader with two years after its establishment was a bold innovation and practice in the field of innovative agricultural services. "Down to earth" is the key to the success of Cloud Farm. In order to keep close connection with farmers and provide the help of communication, consulting, ordering assistance, logistics, and picking on demand, the Cloud Farm established village and town service stations as well as the position of "station agent", so that farmers feel the fun and benefits of online shopping--just moving fingers, cheap and high-quality agricultural commodity can be directly delivered to the fields. All of these not only increase user stickiness, cultivate online shopping habits, but also drive online product sales and development through high-frequency interaction offline, which achieves both online and offline coordinated development.

Big data will solve the problems of independent system operation, single blockade of information in the traditional agricultural management system, as well as opening up the links between agriculture and other industries such as the financial industry ${ }^{[1]}$. At the same time, when a large amount of user data is accumulated, more agricultural big data will be excavated to integrate the data in different agricultural production fields, providing an all-around and three-dimensional data delineation to understand and reshape customer needs from a system perspective, so as to establish an universally connected, mutually reinforcing and interactive ecosystems. All of the above-mentioned advantages have a great contribution in creating a high-tech ecosystem for the agricultural Internet.

If the business model of Cloud Farm is widely accepted by the market, then, a large number of enterprises with the same type and model will emerge to compete with each other. And as we known, the competition in the internet industry is fiercer than that in the traditional industries. Therefore, shortly, there will be mergers, acquisitions, and reorganizations among various agricultural E-commerce suppliers and enterprises. Driven by marketization, there will be a trend of oligopoly in 
the agricultural E-commerce industry ${ }^{[2]}$. A few e-commerce enterprises that integrate technology and services will stand out and dominate the entire industry.

The success of the Cloud Farm model could hugely ascribe to the building of the offline service center and service engineer team, the "rural agency" and the "Cloud Knight". In the future, with the continuous development of the Cloud Farm and the expansion of business coverage areas, the number of offline marketing and service staff will continue to grow. Then, the professional knowledge and service skills of front-line staff will determine the development of enterprises ${ }^{[3]}$. Therefore, enterprises must establish a long-term training mechanism to improve the operational capability and level of front-line market personnel for long-term development needs.

\section{References}

[1] GUAN F X. Form and Evolution of Modern Agricultural Enterprise Organization in China[J]. Research of Agricultural Modernization, 2009.

[2] SHENG L, MING L. The circulation economy pattern of agricultural industrialization enterprise: a case study of Tianguan enterprise group in Henan.[J]. Journal of China Agricultural University, 2004.

[3] GU B X, WANG Y H, LI Y P. Study on the Spatial Organization of Organic Agricultural Enterprise Network in China[J]. Applied Mechanics \& Materials, 2014,522-524:1782-1790. 